\title{
房屋建筑结构设计中优化技术的应用
}

\author{
齐兆辉* \\ 华汇结构设计事务所（东营）有限公司，山东 257000
}

\begin{abstract}
摘 要: 在我国经济社会的不断进步与发展中, 我国经济水平的不断提升, 使人们的生活质量与生活水平也有所 提升, 而且对房屋建筑结构的优化设计提出了更高的要求。所以, 为了达到房屋建筑结构设计的标准, 就必须不断提 升工作人员与设计人员的专业水平与工作能力, 将设计人员的设计理念与房屋建筑结构设计有效结合, 在最大程度上 全面提升其结构设计的水平与质量，同时在安全性与实用性的方面达到标准要求，并且达到统筹兼顾的作用。
\end{abstract}

关键词：房屋建筑；结构设计；优化技术

\section{Application of Optimization Technology in Building Structure Design}

\author{
Zhao-Hui Qi* \\ Huahui Structural Design Agency (Dongying) Co., Ltd., Dongying 257000, Shandong
}

\begin{abstract}
With the continuous progress and development of China's economy and society, the continuous improvement of China's economic level has improved people's quality of life and living standards, and put forward higher requirements for the optimal design of housing construction structure. Therefore, in order to meet the standard of building structure design, we must constantly improve the professional level and working ability of staff and designers, effectively combine the design concept of designers with building structure design, comprehensively improve the level and quality of structural design to the greatest extent, meet the standard requirements in terms of safety and practicability, and achieve the role of overall consideration.
\end{abstract}

Keywords: Housing building; Structural design; Optimization technology

一、引言

近几年以来, 在不断深人我国建筑行业的背景下, 需要不断创新与全面优化房屋建筑结构的设计技术, 还需要提 升建筑行业在市场行业中的竞争能力, 确保其有效实现建筑行业的稳定发展 ${ }^{[1]}$ 。因此, 设计人员需要在工作之前完成 前期的调查与准备工作, 深人分析与详细了解房屋建筑的相关信息, 采用完全合适的优化技术, 在最大程度上全面提 升建筑结构设计的质量 ${ }^{[2]}$ 。与此同时, 在设计的过程中, 不仅需要全方位考虑建筑结构的安全性与经济性, 同时还需 要兼顾美观性与舒适性。只有设计人员兼顾不同方面的需求, 才能够充分发挥结构设计方案在后期工作的指导性作 用，同时满足了建筑行业与房屋住户的实际需求。

\section{二、房屋建筑结构设计优化的概念}

（一）房屋建筑结构设计中优化技术的原则

房屋建筑结构设计的优化技术, 不仅可以提高经济利用的价值, 同时还可以高度重视相应的问题。因此, 设计人 员同管理人员需要对问题进行详细了解, 首先, 将结构设计所应用的技术进行全面优化, 将房屋建筑的材料合理运 用, 保障房屋建筑材料和设计方案完全统一 ${ }^{[3]}$, 从而在最大程度上进行有效协调。与此同时, 房屋建筑结构设计不仅 需要按照人们的审美标准进行设计, 同时还需要完全符合安全性的标准, 保障其质量与安全性, 只有不断完善房屋建 筑的结构设计, 才能够在一定程度上满足人们对房屋建筑结构设计的需求。

(二) 房屋建筑结构设计中优化技术的特点

*通讯作者: 齐兆辉, 1983年11月, 男, 汉族, 山东东营人, 任职于华汇结构设计事务所 (东营) 有限公司, 助 理工程师, 大专。研究方向: 结构设计。 
在房屋建筑的结构设计中，设计人员在房屋建筑结构设计的同时需要全方位保障其结构的安全性，不断减少相关 设计人员在实际工作中的工作压力。其结构设计的特点包括以下几个方面。

其一，从结构设计的角度出发，需要结合不同结构的设计要求，在规定时间内进行设计，同时还需要采用因地制 宜的原则，确保房屋建筑结构在实际社会中采用优化技术，从而有效开展 ${ }^{[4]}$ 。

其二, 为了确保房屋建筑物的外观设计十分美观, 就必须加大对房屋建筑物的外观设计。由于现代社会的人们在 外观上有所追求, 所以必须结合人们的实际情况与设计观念, 为人们构建完全符合审美标准的房屋建筑物, 同时在这 种情况下有效应用优化技术。

其三，从安全的角度出发，在设计人员设计外观中，在最大程度上需要全方位充分考虑其安全性与稳定性，不可 为了追求经济效益的最大化而不保障安全与质量。所以, 为了保障房屋建筑结构设计达到标准要求, 就必须保障房屋 建筑结构设计的稳定性，从而保障房屋建筑结构设计方案完全符合建筑行业的标准。

\section{（三）房屋建筑结构的设计的含义}

在进行房屋建筑结构设计的过程中, 明确其设计概念是非常重要的, 是保障房屋建筑结构设计能够顺利进行的前 提条件。所谓的设计概念就是设计人员已按照自身的设计经验和专业技能, 结合客户的实际需求而开展一系列的设 计工作, 还要充分考虑各项因素对房屋建筑结构施工过程可能带来的影响问题, 不但提高房屋建筑结构设计的实用效 果, 而且还能达到客户对房屋结构的个性化要求。其目的就是将房屋的建筑结构设计成具有先进施工技术、美观的建 筑造型、多元化的居住空间的工程项目。

\section{三、房屋建筑结构设计优化的必要性}

(一) 有利于降低工程造价

从房屋建筑工程造价的角度分析, 设计时期对房屋工程总造价的影响占据着百分之五十至百分之七十左右。同时 将优化设计应用在房屋建筑的设计环节当中, 在满足房屋建筑安全性与经济性的同时, 需要采用有效的方式控制工 程造价，有利于为建筑行业节省大量的资金费用 ${ }^{[5]}$ 。比如，房屋建筑的层数与经济效益两者之间有着一定的联系，当 然，房屋楼层的层数越多，则容纳的住户就越多，但为了防止光线的遮挡，必须将楼与楼之间的间距不断扩大。

与此同时，在房屋建筑结构的设计中，需要采用优化技术，利用科学合理的设计方式对建筑层高进行设计，同时 还需要保障建筑行业经济利益的最大化。另外, 在建筑结构应用优化设计的过程中, 必须缩短房屋建设的工程周期、 不断节约建筑材料的应用以及人工合理的配置等，其中最为重要的就是控制工程造价，防止出现不必要的资金浪费。

\section{(二) 有利于提升建筑安全}

在房屋建筑结构设计的同时, 其设计方案在工程中有着至关重要的作用，房屋建筑结构设计必须按照其依据进行 设计，同时其在一定程度上决定了房屋建筑质量与安全 ${ }^{[6]}$ 。所以，在设计方案的同时，相关设计人员必须将安全摆在 房屋建筑工程中的首要位置。由于房屋建筑结构相对复杂，而且其功能需求十分多样化，给相关的设计人员带来了巨 大的压力。设计人员必须对房屋建筑结构的协调性加以考虑，在细节上需要全方位考虑其功能与实用性。

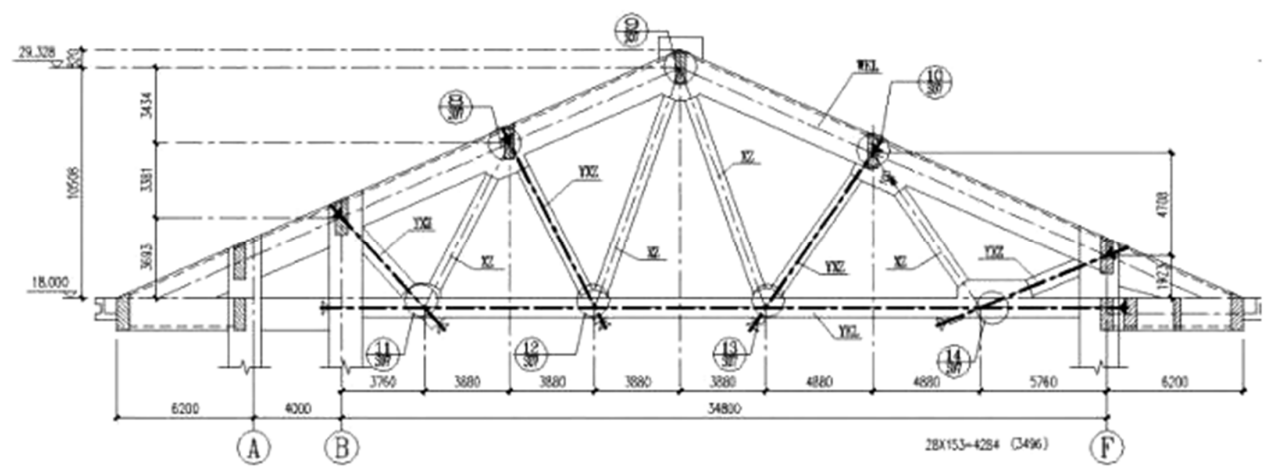

图1 房屋建筑结构优化设计的实际操作

针对这一现象, 需要借助于BIM系统, 将BIM系统当作房屋建筑结构设计的辅助方法, 不断提升房屋建筑结构在 设计中的质量与安全。比如, 在结构设计中应用BIM系统的同时, 为达到最佳效果, 还需要在虚拟的环境下逐渐形成 
$3 \mathrm{D}$ 模型, 只有通过这种方式, 才能够保障相关设计人员及时发展结构设计的问题, 提出相应的有效对策与方式, 从而 全面优化相关设计人员的设计方案。如图1所示。

\section{四、房屋建筑结构设计中优化技术的应用步骤}

\section{(一) 选择设计变量}

当相关设计人员在房屋建筑结构设计的过程中, 可以根据以往的设计经验, 与实际情况有效结合, 选择相对较为 重要的指标作为房屋建筑结构的设计变量, 结构的可靠度与损失期望等这两个方面可以当作设计变量 ${ }^{[7]}$ 。与此同时, 还可以设计非核心的指标, 在最大程度上将建筑结构的局部设计当作参考变量, 并且将其不计人在房屋建筑结构设计 的设计变量当中, 进而减轻了相应的设计压力。除此之外, 将相应的设计变量进行不断汇总, 结合实际情况与不同程 度分别赋予权重，从而在规定时间之内将其数据保存在参数库当中。如图 2 所示。

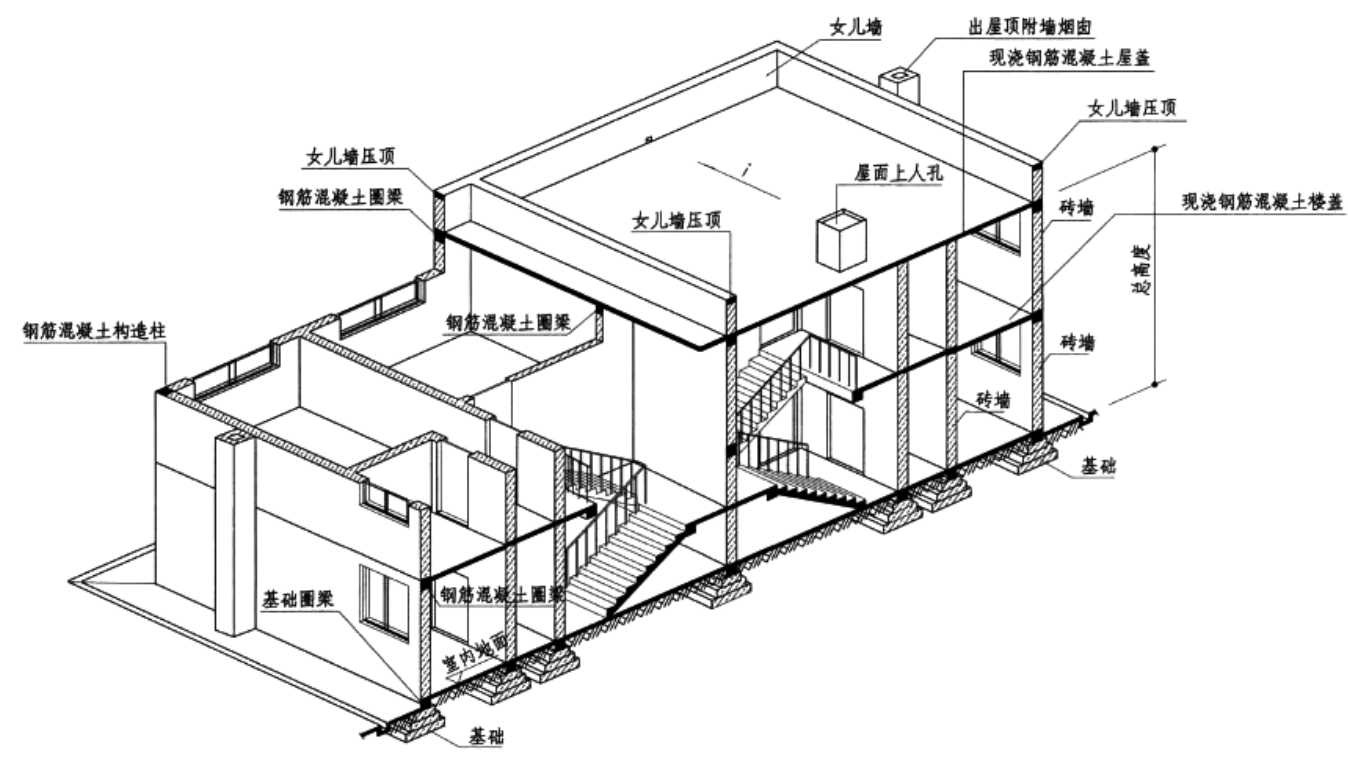

\section{（二）明确约束条件}

图2 房屋建筑结构的优化设计图

根据房屋建筑现场的施工规范与要求, 必须在其中设定相应的约束条件。与此同时, 在建筑结构优化设计的同 时, 倘若设计已经超过了约束的条件, 则这就说明了相应的设计方案不合格, 而且完全不符合标准要求, 所以相关设 计人员需要及时发现问题, 采用优化技术让其达到约束的条件 ${ }^{[8]}$ 。因此, 以不同设计的角度分析, 相关设计人员选取 的约束条件有着一定的差距。比如, 在房屋建筑安全的角度出发, 其约束条件有着结构相对较强等; 在工程造价的角 度分析, 约束条件有了材料的消耗以及设备的应用情况。所以, 这就需要相关设计人员在设计约束条件的同时, 需要 详细记录与深人分析, 只有这样在结构设计中, 才可以全面保障结构设计完全符合标准, 并且在一定程度上达到设计 目标。
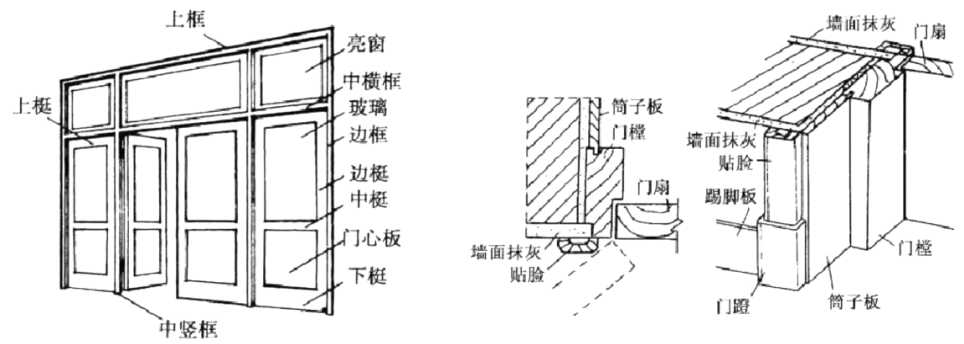

图3 房屋建筑结构门窗设计图

（三）编制优化方案 
由于高层建筑的结构相对复杂, 而且有着功能多样化的基本特点, 使得在实际设计工作中给相关设计人员在结构 设计上带来了全新的挑战。因此，在编制结构设计优化方案的过程中，必须从多个不同的角度出发，全方位考虑其 变量, 并且保障设计方案在设计完成之后有着协调性。与此同时, 房屋建筑结构设计在采用优化设计的同时, 可以借 助于诸多的辅助工具, 比如复合形法等, 采用这种方式可以全面优化其设计条件。另外, 在编制设计方案初步完成之 后，相关设计人员需要对其进行验证，不仅要保障建筑结构之间的协调，同时还要保障设计方案完全符合标准需求。 如图3所示。

（四）设定优化程序

在实际应用计算机技术的同时, 将 $\mathrm{CAD}$ 软件作为辅助设计软件, 在房屋建筑模型构建的同时, 需要完全应用优化 技术。所以, 只有将设计人员提出的设计方案, 全面融人在房屋建筑的模型当中, 在其运行的同时, 可以更加直观地 展示相应的设计结果。与此同时, 相关设计人员需要按照设计结果, 在其中寻找不足之处, 通过优化技术在以往的结 构设计方案中采用针对性的方式全面优化。针对实时监测 $\rightarrow$ 及时发现问题 $\rightarrow$ 结构设计优化 $\rightarrow$ 再次监测的全部过程, 只 有这样才能够有效实现房屋建筑结构设计的全面优化，从而满足设计的预期效果。

\section{五、结束语}

综上所述，建筑行业在房屋结构设计中有着决定性的作用，其质量与安全在建筑行业中十分重要，必须对其予以 有效保障。由于房屋建筑结构设计方面相对复杂, 为了保障其安全性与质量, 就必须在结构设计当中全面应用优化技 术, 通过对设计方案的不断完善与改进, 在最大程度上为后续房屋建筑的施工提供诸多参考依据。与此同时, 在设计 人员设计的同时, 需要不断提升设计能力与设计水平, 不断尝试与大胆尝试全新的业务技能, 并且完全把握相关的设 计软件，从而在房屋建筑结构设计中将优化设计全面应用在其中，使得我国建筑行业在当今社会中可持续性发展。

\section{参考文献:}

[1]司霜.探析房屋建筑结构设计中优化技术的应用[J].中国建筑金属结构, 2021(6):76-77.

[2]何华.房屋建筑结构设计优化技术应用策略——以异形柱框架为例[J].装饰装修天地, 2021(3):93.

[3]何华. 房屋建筑结构设计优化技术应用策略———异形柱框架为例 [J]. 装饰装修天地, 2021(3):93.

[4]孟祥华.房屋建筑结构设计中优化技术应用价值研究 [J].陶瓷, 2020(12):108-109.

[5]罗智武.探讨房屋建筑结构设计中的优化技术应用 [J].建材与装饰, 2020(3):99-100.

[6]何辉,吴海,刘致君.房屋建筑结构设计中优化技术应用探讨[J].城市建筑, 2020,17(30):119-121.

[7] 郭晓建.房屋建筑结构设计中优化技术的应用浅析[J].建材发展导向(上), 2020,18(11):176.

[8]刘俊玲.房屋建筑结构设计中优化技术的应用分析[J].山西建筑, 2019,45(10):35-36. 